\title{
KINETICS STUDY OF ORGANIC MATTER ADSORPTION FROM HIGH STRENGTH PHOSPHORIC ACID ONTO ACID ACTIVATED SODIUM-BENTONITE
}

\author{
M. M. Ali, ${ }^{1}$ Azza A. Attia, ${ }^{2}$ M.H. Taha*, ${ }^{1}$ M. M. El-Maadawy, ${ }^{1}$ and A. M. Abo-Raia ${ }^{1}$
}

${ }^{1}$ Nuclear Materials Authority. P.O. Box 530, El Maddi, Cairo, Egyp

${ }^{2}$ Chemistry Department, Faculty of Science, Zagazig University,

\begin{abstract}
This study analyzed the structural transformations and adsorption properties of Na-bentonite clay before and after chemical activation by sulfuric and hydrochloric acids. The untreated and treated samples were characterized using Xray Fluorescence, X-ray diffraction and Fourier Transform Infrared (FTIR) Spectroscopy. The adsorptive capacities of the samples were investigated by using them to adsorb organic matter from high strength phosphoric acid. The experimental data exhibited that the clay treated with sulfuric acid caused highest organic matter adsorption capacity. The kinetic models of adsorption were analyzed by the pseudo-first order, pseudo-second order, Elovich kinetic and Morris-Weber models. The results have been indicated that the pseudosecondorder kinetic model is more appropriate than the others for natural bentonite but for chemical activated clays pseudo-first order is fitting.
\end{abstract}

Keywords: organic matter, adsorption, phosphoric acid, and sodium bentonite.

\section{Introduction}

Phosphoric acid is the second most produced acid after $\mathrm{H}_{2} \mathrm{SO}_{4}$. Commercially, phosphoric acid is manufactured using different processes, the most commonly used are: thermal and wet-process. The wet-process involves reaction of phosphate rock with an acid (mainly sulfuric acid) (Slack, 1968). The wet process phosphoric acid is accompanied by a number of undesirable ionic impurities, like (fluoride, iron, copper, etc.) and organic matter (OM) such as humic substances like fulvic acid and humic acid (HA). Many of these impurities, particularly the solid impurities, are removed from the acid by techniques such as clarification. The presence of these impurities affects the quantity and the quality of the 
product. For this reason, about $95 \%$ of the acid produced by the wet process is directly used as fertilizer $\mathrm{s}$ and excluded from use in non-fertilizer applications (Fuentes, et al., 2013).

Many research techniques have been investigated for the removal of OM from wet process phosphoric acid (WPA), such as ion exchange (Koopman, et al., 2002); precipitation (Kijkowska, et al., 2002); ionic flotation (Min-Yun, et al., 2004); solvent extraction (Awwad, et al., 2000); membrane processes like electrolysis, reverse osmosis, and nano filtration (Bendada, et al., 2001); adsorption on activated carbon (Mellah, et al., 1994); crystallization (Hannachi, et al., 2007); extraction with chelating or impregnated resins (Booker, et al., 1988); and concentration or addition of additives (Bishnoi, et al., 2004). Although these methods have been widely employed, they have several drawbacks such as high operating and waste treatment costs, high consumption of reagents, and large volume of sludge formation (Olyaie, et al., 2012). However, due to their high cost and sometimes low availability, their use is not as feasible as it should be. Therefore, cost-effective alter-native technologies or adsorbents for the treatment of metal and OM containing WPA are needed (MeIIah, et al., 2006).

Clay minerals divided into four main groups: kaolinite group, illite group, smectite group, and vermiculite. The basic structural unit of smectite clay is a layer consisting of two inward-pointing tetrahedral sheets with a central alumina octahedral sheet (Fig. 1) (Komadel, 2003). The layers are continuous in the $\mathbf{a}$ and $\mathbf{b}$ directions, but the bonds between layers are weak and have excellent cleavage, allowing water and other molecules to enter between the layers causing expansion in the c direction.

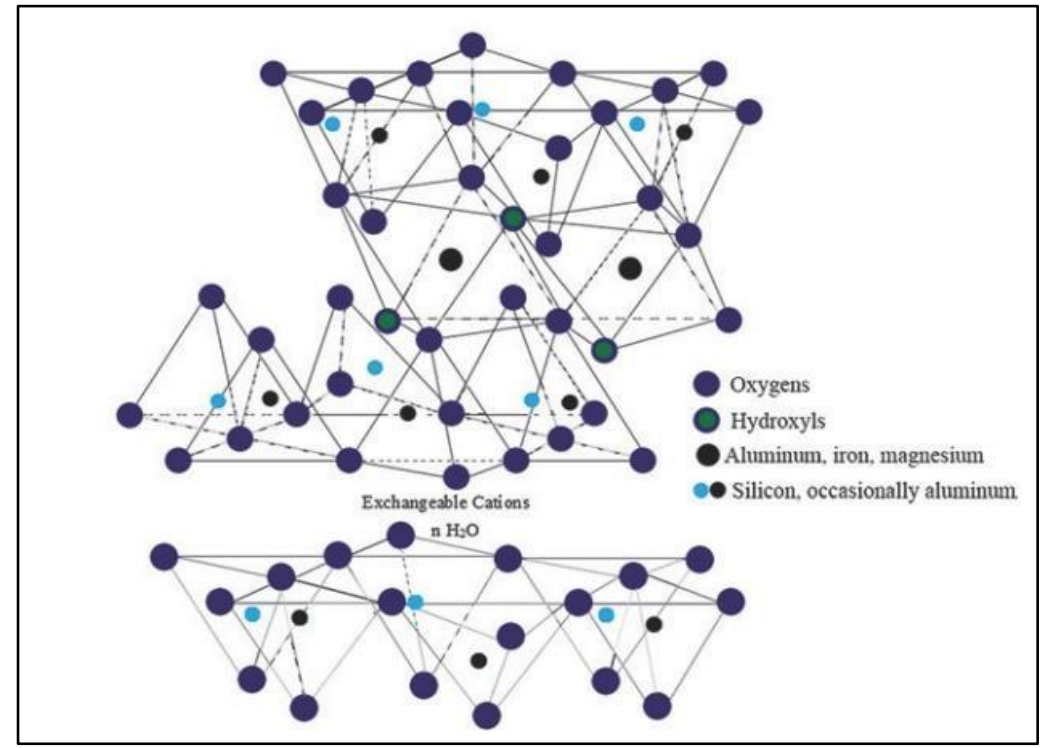

Figure (1): The structure of bentonite clay (Komadel, 2003). 
The general molecular formula of smectite group is;

$$
(\mathrm{Ca}, \mathrm{Na}, \mathrm{H})(\mathrm{Al}, \mathrm{Mg}, \mathrm{Fe}, \mathrm{Zn})_{2}(\mathrm{Si}, \mathrm{Al})_{4} \mathrm{O}_{10}(\mathrm{OH})_{2-\mathrm{x}} \mathrm{H}_{2} \mathrm{O}
$$

One characteristic in smectite clay is considerable substitution in the octahedral sheet and some of the tetrahedral sheet.

Calcium montmorillonite and sodium montmorillonite are the most important clay minerals in smectite group. The main structural difference between calcium and sodium montmorillonite is at the water layer, calcium montmorillonite possesses two water layers in the interlayer position while for sodium montmorillonite has only one water layer (Komadel, 2003). With only one water layer in the interlayer position, sodium montmorillonite has significantly different properties with calcium-bentonite. Sodium montmorillonite has the much higher swelling capacity and viscosity than calcium montmorillonite.

Bentonite clay contains at least $75 \%$ of montmorillonitic mineral. The rest are other aluminosilicates, mainly kaolinite, illit, glauconite, chlorite, vermiculite, silica, and others. Furthermore, fragments of older rocks occur as quartzite, sandstone, decalcified clays, and gneisses. These rocks and minerals, which may occur in bentonite, are considered as pollutants, they negatively affect the technological properties, which depend on the presence of montmorillonite.

Chemical modifications on the clays surface with mineral acid solution, usually sulfuric or hydrochloric acids were conducted to improve the clays adsorption capacity by increasing the specific surface area (SSA), porosity and increase the overall negative charge (Awwad, 2013).

Clays have been applied for the removal of organic matter from commercial phosphoric acid (Khoualdia, et al., 2017). In this contribution and regards to environmental aspect, this paper deal aims to investigate the organic matter adsorption from commercial phosphoric acid by bentonite and acid activated clays materials by batch kinetics and equilibrium studies.

\section{Experimental}

\section{Materials and Reagents}

$\mathrm{H}_{2} \mathrm{SO}_{4}$, and $\mathrm{HCl}$ acids were chemical reagent grade and were supplied from ADWIC, Egypt. Natural sodium bentonite (NSB) clay was obtained from $\boldsymbol{A} \boldsymbol{l}$ Amier Ceramic Co. Cairo. The provided clay samples were crushed, ground in a mortar and sieved to the used grain size of 200 mesh size. The clay samples were purified by water gravitational sedimentation. The washed solid clay sample was dried in electric furnace at $110{ }^{\circ} \mathrm{C}$ until complete dryness.

Crude high strength phosphoric acid under study was produced from Abu Zaabal Company for Fertilizer and Chemical Materials (AZFC), its chemical composition is given in (Table 1). 
Table (1): Chemical analysis of crude phosphoric acid.

\begin{tabular}{cc}
\hline Component & Concentration \\
\hline $\mathrm{P}_{2} \mathrm{O}_{5}$ & $\approx 45.0 \%$ \\
$\mathrm{Ca}$ & $0.44 \%$ \\
$\mathrm{SO}_{4}$ & $5.84 \%$ \\
$\mathrm{SiO}_{2}$ & $0.96 \%$ \\
$\mathrm{~F}$ & $1.20 \%$ \\
$\mathrm{Fe}$ & $2.40 \%$ \\
$\mathrm{OM}$ & $1000 \mathrm{ppm}$ \\
\hline
\end{tabular}

\section{Preparation of modified bentonite}

Acid activation of natural bentonite has been carried out by treating the natural bentonite clay sample with hydrochloric and sulfuric acids [ $\left.\mathbf{R}(\mathbf{H C l})-\mathbf{R}\left(\mathbf{H}_{2} \mathbf{S O}_{4}\right)\right]$. Sulfuric acid-activated bentonite

Sulfuric acid activated bentonite (SAB) was conducted by adding $50 \mathrm{~g}$ of bentonite to $500 \mathrm{~mL}$ of sulfuric acid solution $(2 \mathrm{M})$ and refluxing at $110^{\circ} \mathrm{C}$ under atmospheric pressure for 4 hours. The activated solid was washed with distilled water until free from sulfate and dried at $80{ }^{\circ} \mathrm{C}$. The dried samples were gently crushed and packed into plastic containers for further use.

\section{Hydrochloric acid-activated bentonite}

Hydrochloric acid activated bentonite (HAB) was prepared by reacting $50 \mathrm{~g}$ of natural bentonite with $100 \mathrm{ml}$ of $3 \mathrm{M} \mathrm{HCl}$ acid solution was added. The mixture was heated on a magnetically stirred hot plate at the temperature of $90{ }^{\circ} \mathrm{C}$ for 150 minutes. After that, the resulting sample was washed with hot distilled water until free from chloride anions and then sample was dried up at $60^{\circ} \mathrm{C}$.

Natural bentonite (NB), Sulfuric acid activated bentonite (HAB), and Hydrochloric acid Activated Bentonite (HAB) clay samples were pulverized, homogenized and sieved to homogenized particle sizes of 200 mesh size. The samples were stored under vacuum condition in a desiccator for further analysis.

\section{Clay samples characterization:}

The mineralogical analysis of NB, SAB, and HAB clay samples have been carried out by using a powder X-ray diffractometer (model XD1180, Schimadzu, Japan) equipped with a copper target and a nickel filter.

\section{Apparatus:}

The reaction was carried out in a cylindrical $250 \mathrm{ml}$ reactor of $10 \mathrm{~cm}$ diameter. It was fitted with Teflon-coated stirrer with $2 \mathrm{~cm}$ diameter and placed in thermostatically controlled water bath. The impeller tip speed was adjusted at 300 
rpm. Filtration was performed using Buchner type filter of 4.6 inch. diameter. Polypropylene filter cloth of 80 mesh aperture size was used. A vacuum pump was used for filtration.

\section{Experimental procedures}

Unless otherwise stated, Batch adsorption experiments were performed by shaking $1.0 \mathrm{~g}$ of $\mathrm{NB}, \mathrm{SAB}$, and $\mathrm{HAB}$ with $50.0 \mathrm{~mL}$ of the crude phosphoric acid in a thermostated shaker bath at $\left(25 \pm 1^{\circ} \mathrm{C}\right)$. All the experiments were carried out in triplicate and the mean values were presented. Organic matter (OM) concentration in phosphoric acid was determined spectrophotometrically at 418 $\mathrm{nm}$ (Steudel, et al., 2009). The amount of the OM adsorbed was calculated by the difference between the equilibrium concentration and the initial concentration. The amount of OM retained in the solid phase qe $(\mathrm{mg} / \mathrm{g})$ was calculated using the following relation:

$$
\mathrm{q}_{\mathrm{e}}=\left(\mathrm{C}_{\mathrm{o}}-C_{e}\right) \times \frac{V}{m}
$$

Where $\mathrm{C}_{\mathrm{o}}$ and $\mathrm{C}_{\mathrm{e}}$ are the initial and equilibrium concentrations of the $\mathrm{OM}(\mathrm{mg} / \mathrm{L})$, respectively, $\mathrm{V}$ is the volume of the phosphoric acid $(\mathrm{L})$, and $\mathrm{m}$ is the weight of clay used (g). The removal percent of OM from the phosphoric acid is calculated from the following relation:

$$
\text { OM adsorption } \%=\frac{\mathrm{C}_{\mathrm{o}}-C_{e}}{\mathrm{C}_{\mathrm{o}}} \times 100
$$

\section{Results and discussion}

\section{Characterization of raw materials}

The characterization of the Na-bentonite (nature bentonite) NB and different chemical activated clays include $\mathrm{H}_{2} \mathrm{SO}_{4}$ activated $\mathrm{SAB}$ and $\mathrm{HCl}$ activated $\mathrm{HAB}$ have been achieved using XRD.

\section{XRD Study}

X-ray diffraction is a nondestructive analytical technique, which reveals information about crystallographic structure. This technique is widely used in the characterization of clays. The XRD patterns for $\mathrm{NB}, \mathrm{SAB}$ and $\mathrm{HAB}$ are shown in (Fig. 2). The characteristic XRD peaks for the minerals in the clays are presented in (Table 2).

A comparison between $\mathrm{NB}$ and $\mathrm{SAB}$ are illustrated that the most pronounced modification occurs in the montmorillonite peak which shows reduction in intensity as a result of acid attack. On the other hand, a comparison between NB and $\mathrm{HAB}$ showing that $\mathrm{HCl}$ acid concentration of $2 \mathrm{M}$ and temperature caused the 
decomposition of the montmorillonite structure and formation of excess amorphous silica.

Table (2): Chemical composition of the working clay samples

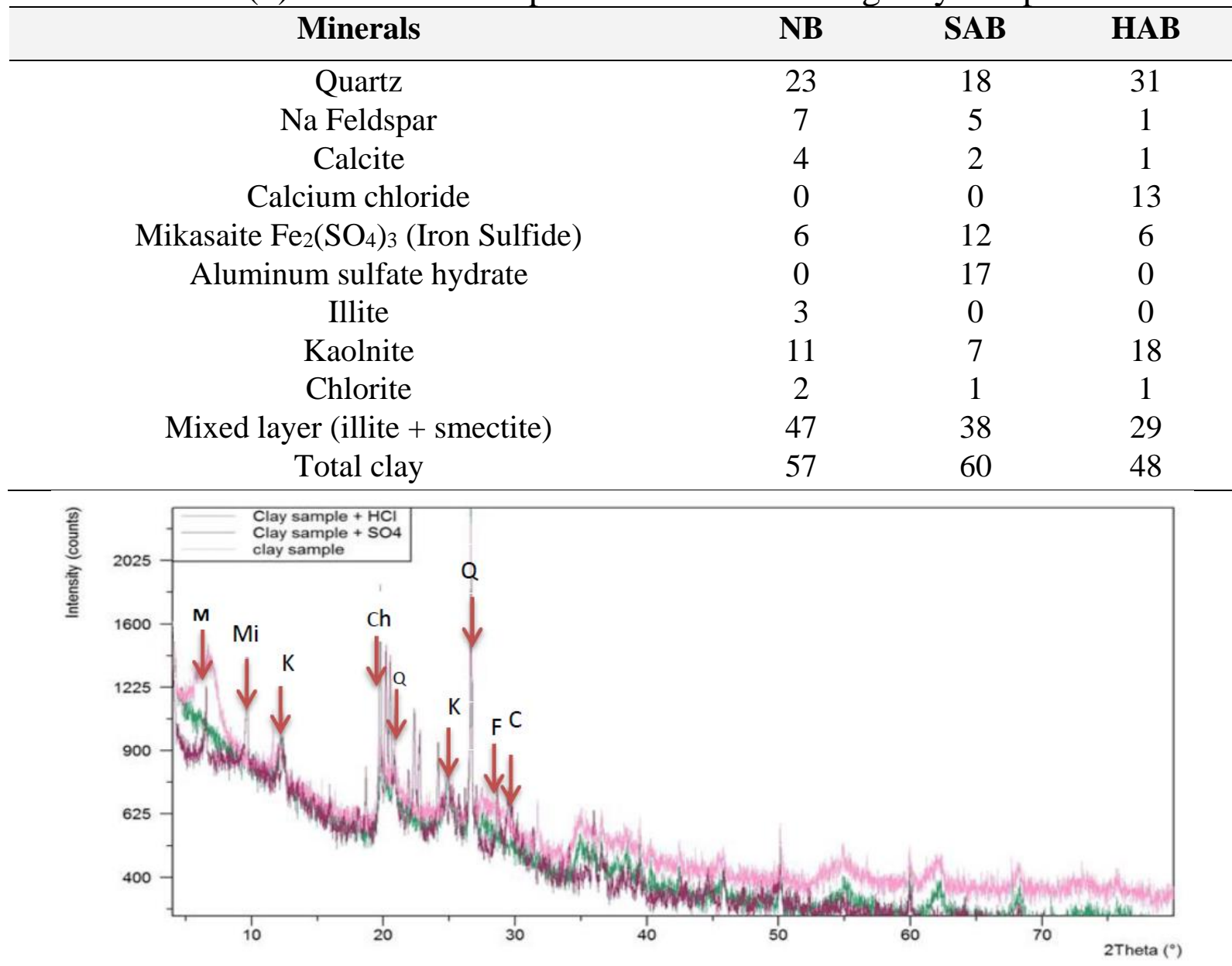

Figure (2): XRD of raw and activated clay (M: Mixed layer "smectite \& illite", Mi: Mikasaite, Q: quartz, F: feldspar, K: kaolinite, Ch: Chlorite, C: Calcite).

\section{Batch investigation}

Organic matter (OM) adsorption from crude phosphoric acid has been investigated by using Na-bentonite (nature bentonite) NB and different acid activated bentonite clays include $\mathrm{H}_{2} \mathrm{SO}_{4}$ activated bentonite $(\mathrm{SAB})$ and $\mathrm{HCl}$ activated bentonite (HAB). The effect of shaking time, clay amount of addition, temperature, mechanical stirring speed and phosphoric acid concentration on the organic matter adsorption efficiency have been studied.

\section{Effect of the adsorption time}

The adsorption time of organic matters by various types of bentonite (NB, SAB and $\mathrm{HAB})$ at different times $(5,15,30,45,60,90$, and $120 \mathrm{~min})$ was carried out. 
$1.0 \mathrm{~g}$ adsorbent was shaken at $50 \mathrm{~mL} 45 \% \mathrm{P}_{2} \mathrm{O}_{5}$ crude phosphoric acid at room temperature. The experimental results are given in (Fig. 3) as a relation between $\mathrm{OM}$ adsorption efficiency $\%$ and time. From the results, it is found that the adsorption of $\mathrm{OM}$ by different types of bentonite is improved with increasing adsorption time until a constant state at $60 \mathrm{~min}$ and there is no significant change after that time. The increasing adsorption rate at the initiation is due to availability of large number of vacant sites for adsorption of OM. (SAB) confirming maximum removal of $\mathrm{OM}$ by eliminating the hydrated and adsorbed water that was already present in the clay during the activation of bentonite using Sulfuric. These results are similar to those obtained by (Chaari, et al., 2008).

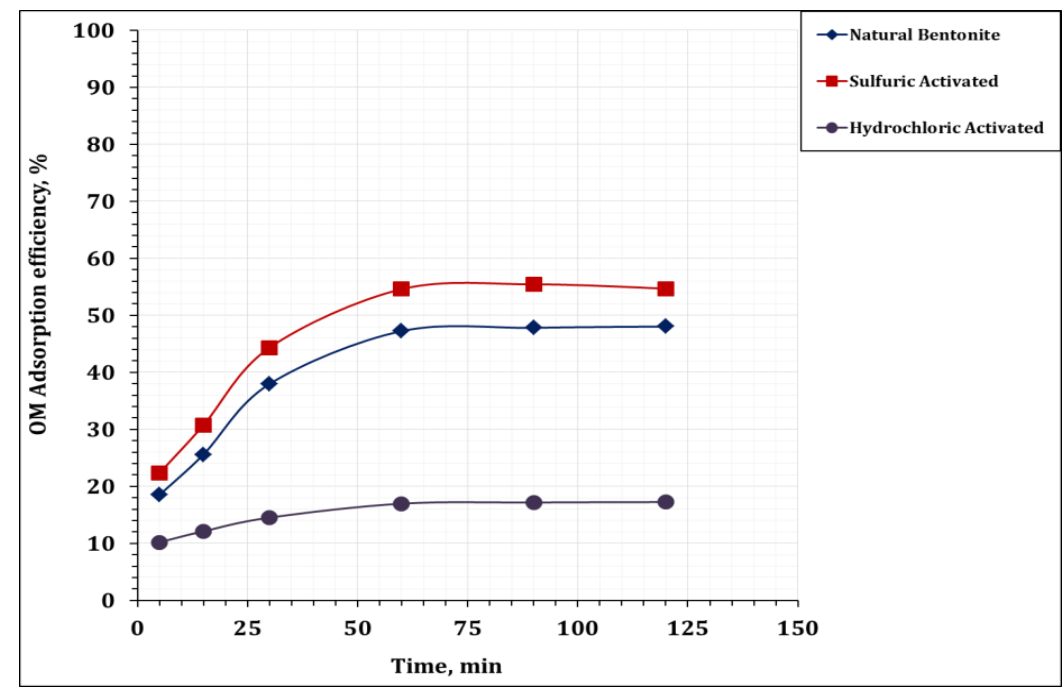

Figure (3): Effect of adsorption time on the organic matter adsorption efficiency, $\%$ (1.0 g different bentonite clays / $50 \mathrm{~mL}$ of $45 \% \mathrm{P}_{2} \mathrm{O}_{5}$ commercial phosphoric acid; room temperature, $400 \mathrm{rpm}$ ).

\section{Effect of the amount of adsorbents}

We followed the evolution of the removal efficiency of organic matter (0.25 - 3 $\mathrm{g} / 50 \mathrm{ml}$ ). Other parameters were reserved unchanging at temperature of about 20 ${ }^{\circ} \mathrm{C}$, crude phosphoric acid, $45 \% \mathrm{P}_{2} \mathrm{O}_{5}$. Measuring the organic matter content of the treated samples was made after 60 minutes contact with the bentonite clays. The obtained data are given in (Fig. 5) as a relation between OM adsorption efficiency $\%$ and clay amount of addition.

The results shown in (Fig. 5) clear that the organic matter removal efficiency raised with increasing dose of bentonite clays introduced. Note that for amount of clay $(1 \mathrm{~g} / 50 \mathrm{ml})$, the best yields 52.6, 60.0 and $18.2 \%$ for $\mathrm{NB}, \mathrm{SAB}$ and $\mathrm{HAB}$, respectively. But the weightier doses of clays cause practically stable in 
adsorption of organic matter due to attainment of equilibrium between the adsorbates and adsorbents (Taha, et al., 2016). Therefore, $(1 \mathrm{~g} / 50 \mathrm{ml})$ was chosen.

\section{Effect of temperature}

The influence of temperature on the organic matter adsorption onto the clays from commercial phosphoric acid, $45 \% \mathrm{P}_{2} \mathrm{O}_{5}$ was carried out at 5 different temperatures ranging from 20 to $60{ }^{\circ} \mathrm{C}$ at solid/ liquid ratio, $1.0 \mathrm{~g} / 50 \mathrm{ml}$, and adsorption time of $60 \mathrm{~min}$. The obtained data are given in (Fig. 5) as a relation between $\mathrm{OM}$ adsorption efficiency $\%$ and temperature. The obtained results indicate that the removal percentage of organic matter is weakly increased with the increase in temperature, indicating that the adsorption process was endothermic in nature. Therefore, the OM adsorption experiments were carried out at room temperature. These results are matching to those obtained by (Acemioğlu, 2004).

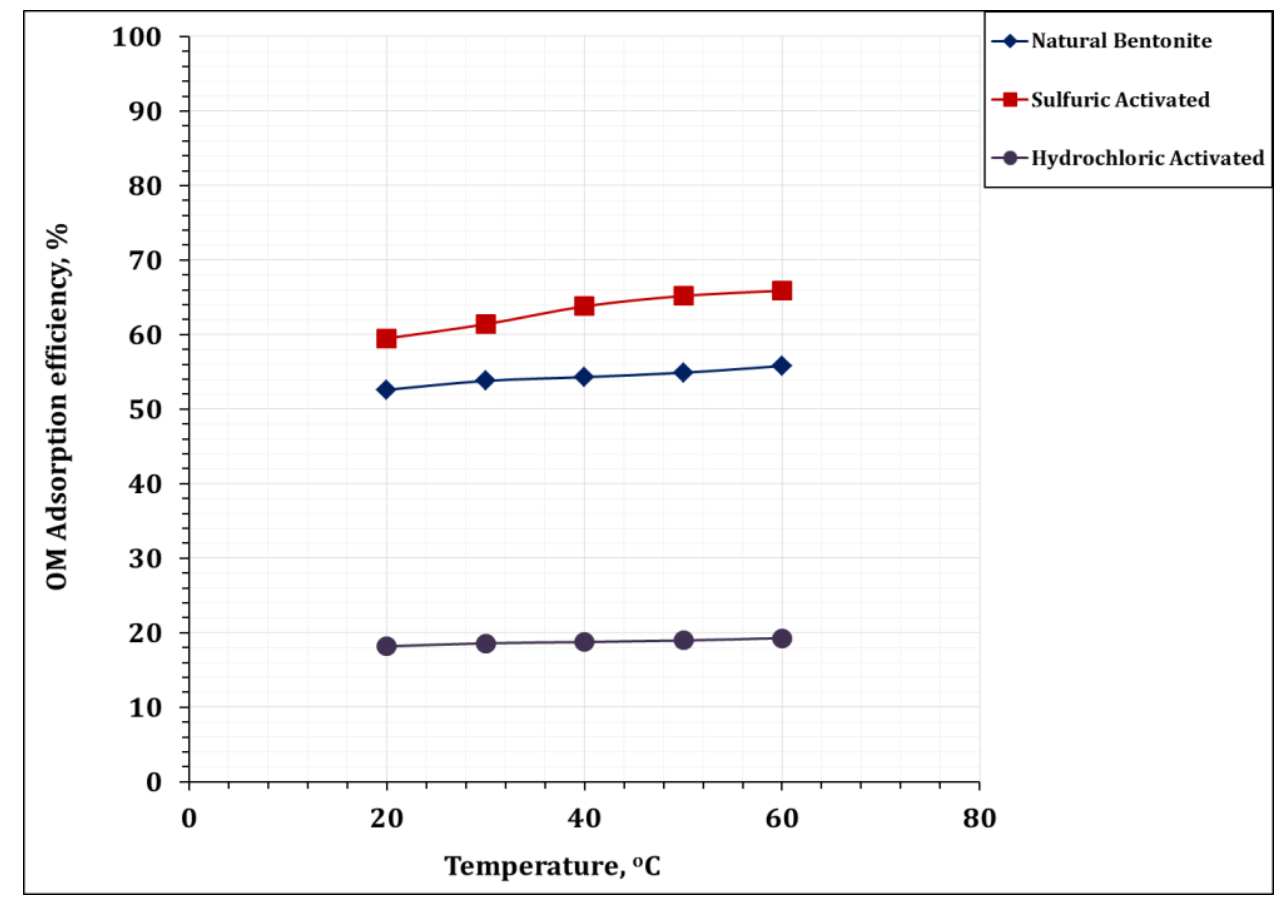

Figure (5): Effect of temperature on the organic matter adsorption efficiency, \% (adsorption time $60 \mathrm{~min} ; 1.0 \mathrm{~g}$ different bentonite clays/ $50 \mathrm{~mL}$ commercial phosphoric acid, $\left.45 \% \mathrm{P}_{2} \mathrm{O}_{5} ; 400 \mathrm{rpm}\right)$.

\section{Effect of Phosphoric Acid Concentration}

Phosphoric acid concentration effect on the organic matter adsorption onto the clays was investigated. The concentration of the feed acid was in the range of 
30-50\% $\mathrm{P}_{2} \mathrm{O}_{5}$ with the following conditions: adsorption time of $60 \mathrm{~min}$, solid/ liquid ratio, $1.0 \mathrm{~g} / 50 \mathrm{ml}$, and at room temperature. The obtained data are presented in (Fig. 6) as a relation between OM adsorption efficiency \% and phosphoric acid concentration. The experimental results show that the adsorption efficiency is decreased by increasing the concentration of phosphoric acid. This may due to the alkaline nature of bentonite (Geethakarthi and Phanikumar, 2011) that neutralizes the acidic $\mathrm{pH}$ of the Phosphoric acid.

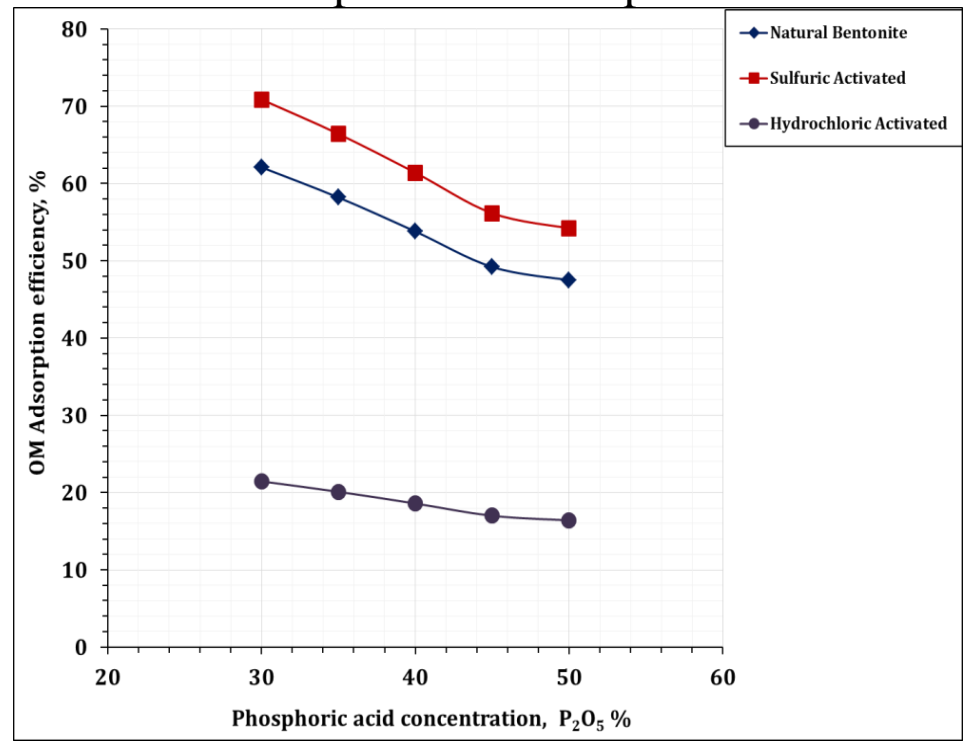

Figure (6): Effect of phosphoric acid concentration on organic matter adsorption efficiency from crude phosphoric acid using different bentonite clays (adsorption time $60 \mathrm{~min} ; 1 \mathrm{~g}$ different clays/ $50 \mathrm{~mL}$ commercial phosphoric acid; room temperature; $300 \mathrm{rpm}$ ).

\section{Effect of agitation speed (rpm)}

Agitation is an important parameter in adsorption phenomena, influencing the distribution of the clay in the bulk solution and the formation of the external boundary film (Inglezakis, et al., 2007). The effect of the agitation on the adsorption of organic matter onto the clays was monitored at several agitation speeds $(100,200,300,400,500 \mathrm{rpm})$ for $60 \mathrm{~min}$. The results are plotted in (Fig. 7) as a relation between $\mathrm{OM}$ adsorption efficiency $\%$ and agitation speed. From the results it is clear that, the organic matter removal percentage is faintly increased as agitation speed increased. High agitation speed plays a critical role, where it causes a decrease in the boundary layer and so decreases the resistance of transportation. Finally, this enhances the transfer rate of organic matter to the surface of the adsorbent, which is called diffusion-controlled mechanism (YS, 2004). 


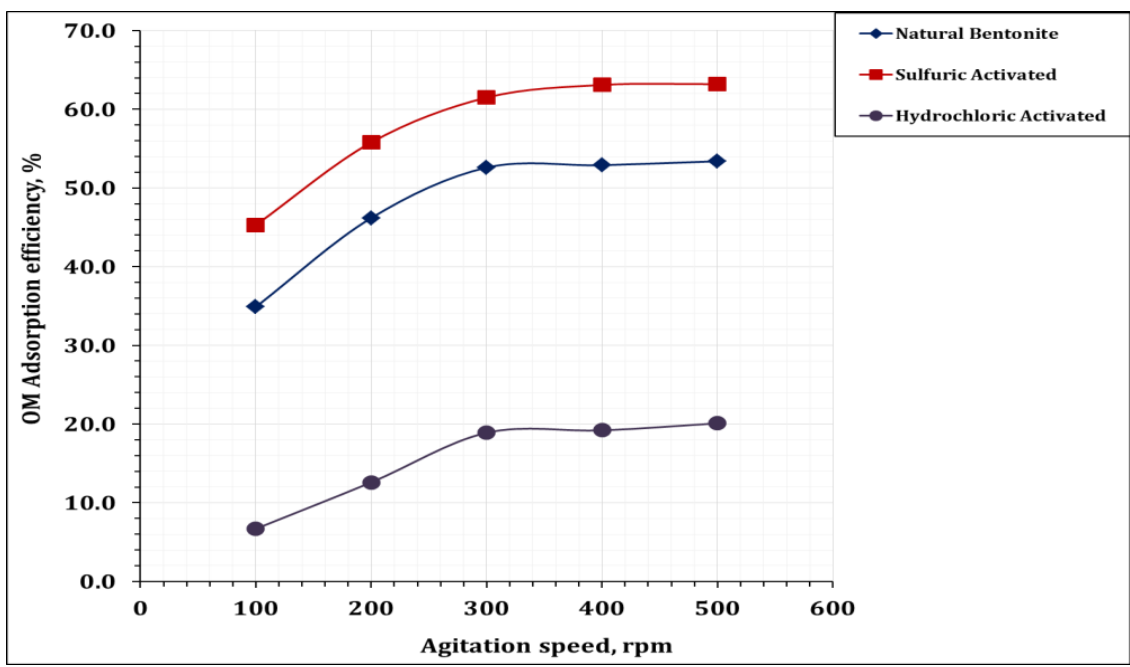

Figure (7): Effect of agitation stirring speed on the organic matter ion adsorption efficiency, $\%$ (shaking time $60 \mathrm{~min} ; 1.0 \mathrm{~g}$ different bentonite clays / $50 \mathrm{~mL}$ commercial phosphoric acid, $45 \% \mathrm{P}_{2} \mathrm{O}_{5}$; room temperature).

\section{Adsorption Kinetic Modeling:}

The mathematical treatment for the obtained results of $\mathrm{OM}$ adsorption from phosphoric acid onto nature bentonite, $\mathrm{H}_{2} \mathrm{SO}_{4}$, and $\mathrm{HCl}$ activated bentonite has been achieved for understanding and developing large scale adsorption process. In this concern, the thermodynamics and dynamics parameters of the OM adsorption process were calculating.

\section{Adsorption kinetic modeling}

An understanding of adsorption kinetics is important to system design parameters such as residence time, which dictate the physical size and flow rates for many unit operations. The kinetics of physical and chemical reactions can be described by a series of models including: pseudo-first order model, pseudo-second order model, Elovich model, and Morris-Weber model.

\section{Pseudo-first-order model:}

The kinetics of adsorption was analyzed by the Lagergren pseudo-firstorder equation as depicted in equation (1) (YS and Mckay, 2000).

$$
\log \left(q_{e}-q_{t}\right)=\log q_{e}-\frac{k_{p_{1}}}{2.303} t
$$

Where $\mathrm{q}_{\mathrm{e}}$ and $\mathrm{q}_{\mathrm{t}}(\mathrm{mg} / \mathrm{g})$ are the adsorption capacities at equilibrium and time $\mathrm{t}$ (min) respectively. $\mathrm{k}_{\mathrm{p} 1}\left(\mathrm{~min}^{-1}\right)$ is the pseudo-first-order rate constant for the kinetic model.

Based on experimental results, linear plot of $\log \left(\mathrm{q}_{\mathrm{e}}-\mathrm{q}_{\mathrm{t}}\right)$ versus time was tested the applicability of Lagergren first order equation to the adsorption of organic matter. The rate constant was calculated from the slope. The effect of dye concentration 
on rate constants $\left(\mathrm{k}_{\mathrm{p} 1}\right)$ helps to describe the mechanism of organic matter removal from high strength phosphoric acid.

\section{Pseudo-second-order model:}

The pseudo-second order equation (Gerente, et al., 2007) is depicted as follows;

$$
\left(\frac{t}{q t}\right)=\frac{1}{k_{2} q_{e}^{2}}+\frac{1}{q_{e}}(t)
$$

Where $\mathrm{k}_{2}$ is the rate constant of pseudo second-order adsorption $\left(\mathrm{g} \mathrm{mg}^{-1} \mathrm{~min}^{-1}\right)$. The plot of $\left(\mathrm{t} / \mathrm{q}_{\mathrm{t}}\right)$ versus $(\mathrm{t})$ of equation (2) should give a linear relationship from which $\mathrm{q}_{\mathrm{e}}$ and $\left(\mathrm{k}_{2}\right)$ were determined from the slope and intercept of the plot, respectively.

\section{Elovich kinetic model:}

The Elovich model equation is generally expressed as (Crank, 1970):

$$
\mathrm{q}_{\mathrm{t}}=\frac{1}{\beta} \ln (\alpha \beta)+\frac{1}{\beta} \ln t
$$

Where $\alpha \ell$ is the initial adsorption rate $\left(\mathrm{mg} \mathrm{min}^{-1}\right)$ and $\beta$ is related to the extent of surface coverage and the activated energy for chemisorption $\left(\mathrm{g} \mathrm{mg}^{-1}\right)$.

The Elovich equation has been shown to be useful in describing chemisorption on highly heterogeneous adsorbents. The initial adsorption rate $\alpha$ and the extent of coverage $\beta$ were calculated from the slope and the intercept of the plot of $\mathrm{q}_{\mathrm{t}}$ against $\ln t$, respectively.

\section{Intra-particle Diffusion-Controlled Adsorption (Morris-Weber model):}

To investigate the internal diffusion mechanism during the adsorption of organic matter onto $\mathrm{NB}, \mathrm{SAB}$, and $\mathrm{HAB}$ clays, the intra-particle diffusion equation has been used, considering that adsorption is usually controlled by an external film resistance and/or mass transfer is controlled by internal $r$ intra-particle diffusion (Weber, et al., 1964). The intra-particle diffusion-controlled adsorption model equation is generally expressed as (McKay, et al., 1980):

$$
q_{t}=k_{\mathrm{i}} t^{0.5}
$$

The coefficient $\mathrm{k}_{\mathrm{i}}$ is determined from the initial linear slope of $\mathrm{q}_{\mathrm{t}}$ versus (time) ${ }^{0.5}$. According to Weber and Morris (McKay, et al., 1980), if the intra-particle diffusion is the rate-limiting step in the adsorption process, the graph of $\mathrm{q}_{\mathrm{t}} \mathrm{vs} . \mathrm{t}^{0.5}$ should yield a straight line passing through the origin. The intra-particle diffusion model can present multilinearity, and three stages can be distinguished. That means that two or three steps can occur. The first portion represents external surface adsorption or an instantaneous adsorption stage. The second portion is a gradual adsorption stage, where the intra-particle diffusion is the controlling factor. The third portion is a final equilibrium stage where the intra-particle 
diffusion starts to decelerate due to extremely low solute concentrations in the solution (Tseng and Juang, 2001).

In respect to the kinetic models, the difference model functions; $\mathrm{q}_{\mathrm{t}},\left(\mathrm{t} / \mathrm{q}_{\mathrm{t}}\right), \log$ $\left(\mathrm{q}_{\mathrm{e}}-\mathrm{q}_{\mathrm{t}}\right)$, and $\ln \left(1-\left(\mathrm{q}_{\mathrm{t}} / \mathrm{q}_{\mathrm{e}}\right)\right)$ as shown in (Figs. 8-11) for natural bentonite and different chemical activated bentonite respectively.

The plots of Lagergren Pseudo-first-order, Pseudo-second-order, Elovich kinetic, and Morris-Weber models for organic matter adsorption from crude phosphoric acid, $45 \% \mathrm{P}_{2} \mathrm{O}_{5}$, using $\mathrm{NB}, \mathrm{SAB}$, and $\mathrm{HAB}$ clays. From the figures a linear relationship was obtained and the parameters of kinetic models with the linear correlation coefficients $\left(\mathrm{R}^{2}\right)$ of each plot are listed in (Table 3).

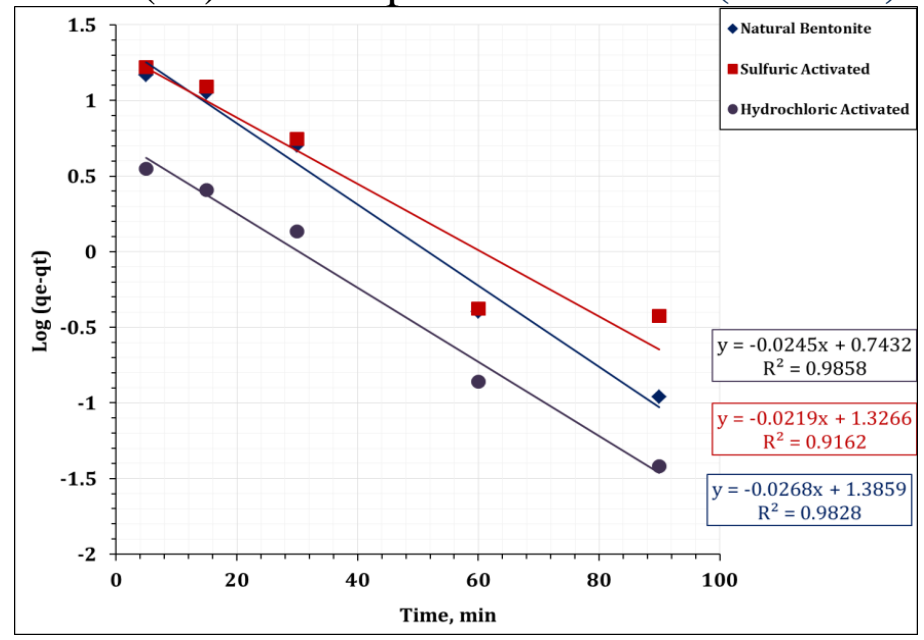

Figure (8): Lagergren plot for organic matter adsorption from phosphoric acid onto natural bentonite, sulfuric and hydrochloric acids activated bentonite.

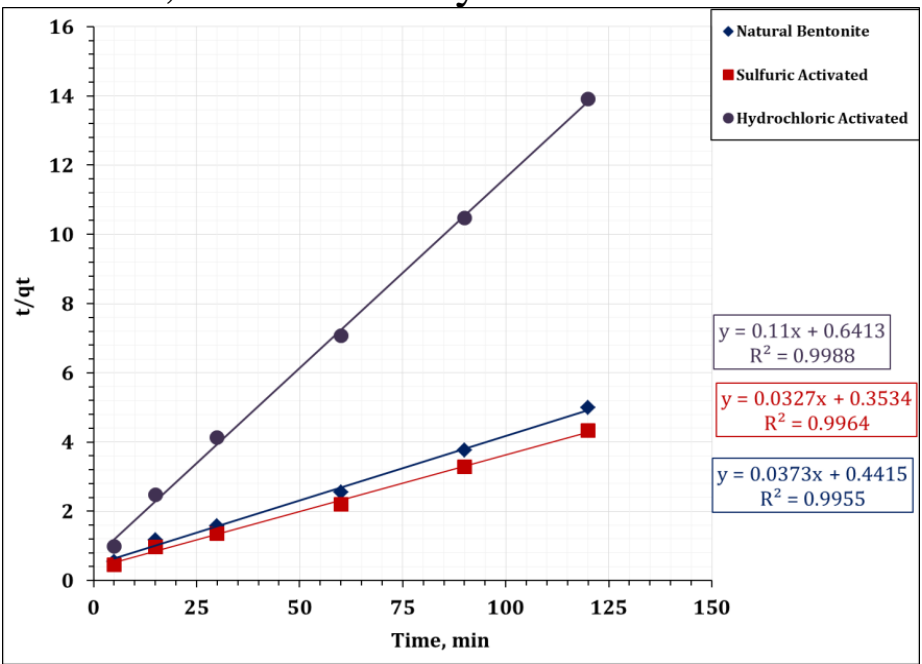

Figure (9): Pseudo- second -order plot for organic matter adsorption from phosphoric acid onto natural bentonite, sulfuric and hydrochloric acids activated bentonite. 


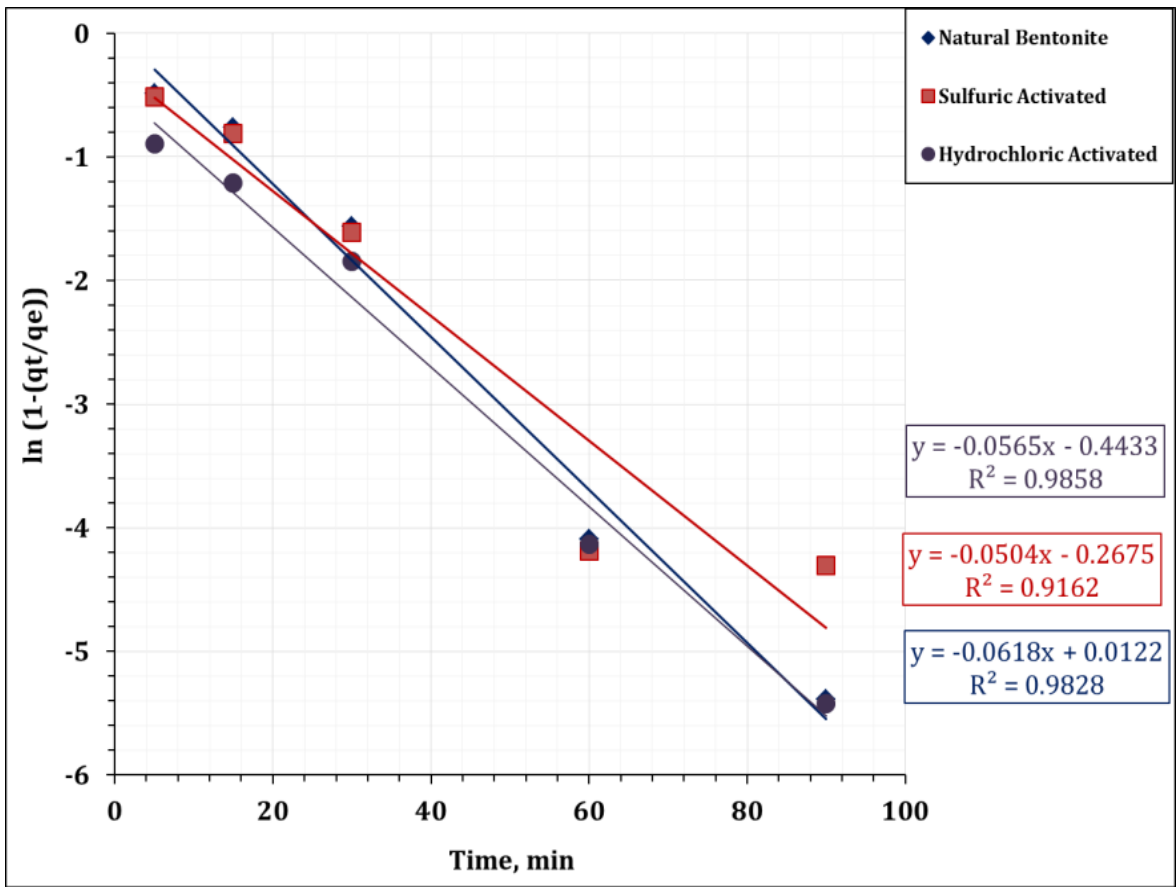

Figure (10): Elovich plot for organic matter adsorption from phosphoric acid onto natural bentonite, sulfuric and hydrochloric acids activated bentonite.

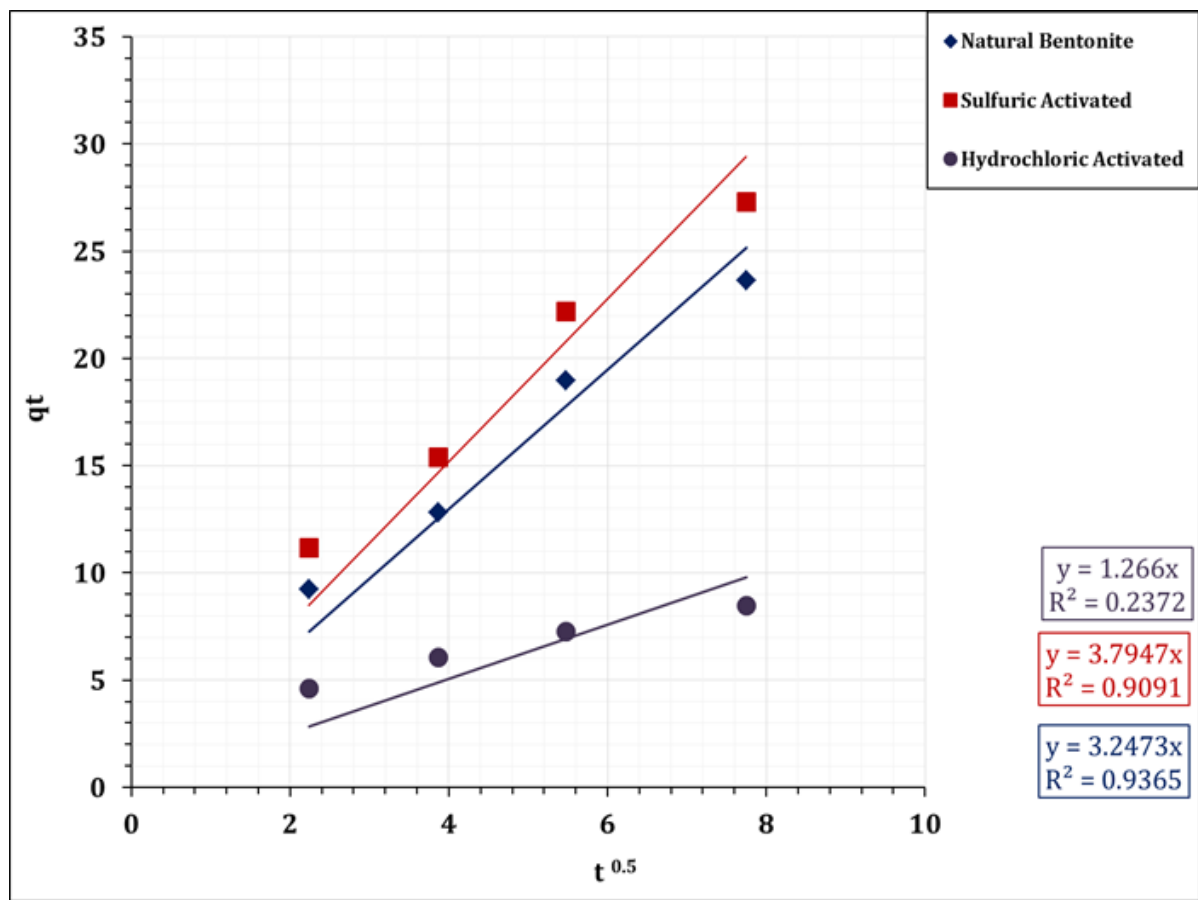

Figure (11): Morris-Weber plot for organic matter adsorption from phosphoric acid onto natural bentonite, sulfuric and hydrochloric acids activated bentonite. 
Table (3): The calculated parameters of the kinetic models with the linear correlation coefficients $\left(\mathrm{R}^{2}\right)$ of each plot.

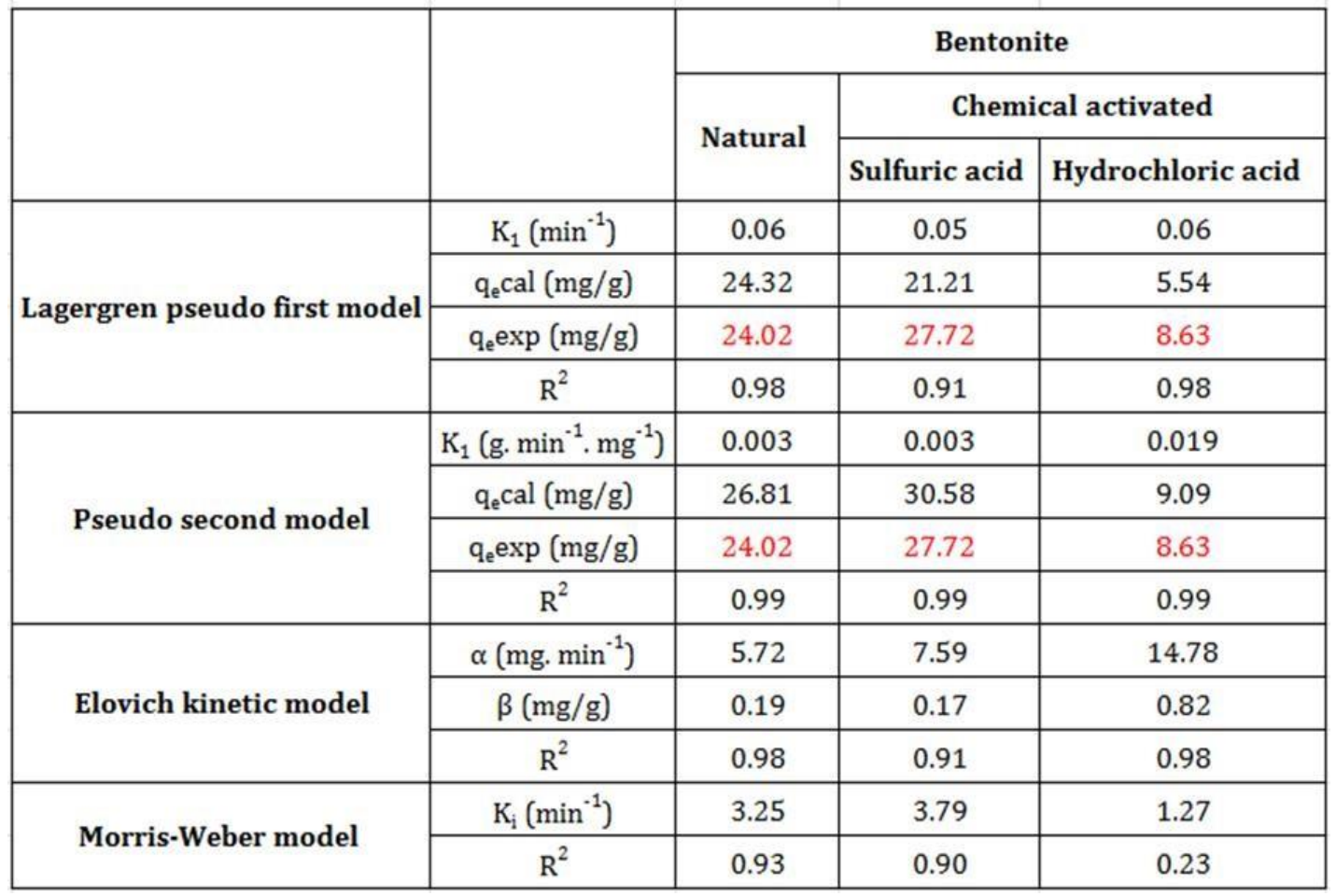

From the results shown in (Figs. 8- 11), it is clear that the Lagergren first order model give straight-line plots for organic matter adsorption onto natural and chemical activated bentonite with an average correlation coefficient of 0.96 , but the calculated values of $\mathrm{q}_{\mathrm{e}}$ dramatically differ from the experimental $\mathrm{q}_{\mathrm{e}}$ values. This means that the kinetic of the adsorption process for NB will follow this model, however the others clays not follow even if it gives high correlation coefficient (Grabowska and Gryglewicz, 2007).

The pseudo second-order model gives straight-line plots for organic matter adsorption onto natural and chemical activated bentonite with an average correlation coefficient of 0.99. By comparing the calculating $\mathrm{q}_{\mathrm{e}}$ values for the second order models with the experimental value of $\mathrm{q}_{\mathrm{e}}$ it is found that the calculated $\mathrm{q}_{\mathrm{e}}$ values are close to the experimental $\mathrm{q}_{\mathrm{e}}$ values for activated clays which confirm that the adsorption process is more appropriately followed the pseudo-second order model.

This suggests that the organic matter adsorption from phosphoric acid, $45 \% \mathrm{P}_{2} \mathrm{O}_{5}$, is chemisorption process which is the result of any shares or exchange of electrons between the organic matter and the functional groups of these adsorbents. This behavior is similar to the adsorption of organic matter from industrial phosphoric acid (45\%) using Fe-pillared bentonite (Hamza, et al., 2013). 
The Elovich model gives straight-line plot for organic matter adsorption onto NB, $\mathrm{SAB}$, and $\mathrm{HAB}$ clays with an average correlation coefficient of 0.95 , which indicated that the adsorption process confirms to the Elovich model. The linear correlations in the Elovich plot suggest that the sorption of organic matter onto natural and chemical activated bentonite have a substantial chemisorption component and the adsorption rate is exponentially dependent on the number of available adsorption sites in the applied clay.

The intra-particle diffusion model plot corresponding to organic matter adsorption from high strength phosphoric acid onto natural and chemical activated bentonite (Figs. 8-11) does not show the stage corresponding to the diffusion of organic matter through the external film. This suggests that the stirring was strong enough to eliminate this resistance.

\section{Conclusions}

In this study, the adsorption of organic matter from phosphoric acid, $45 \% \mathrm{P}_{2} \mathrm{O}_{5}$, using natural and acid activated bentonite was investigated. Results indicate that organic adsorption removal on the clays was considerably affected by different factors such as: temperature, concentration of phosphoric acid, adsorption time, agitation stirring speed and weight of adsorbent. The adsorption process increased with increasing time, weight of adsorbent, temperature and agitation stirring speed and decrease with the increase of concentration of phosphoric acid. The experimental data were tested for different kinetic model expressions and the data were successfully modeled.

\section{References}

Awwad N., Daifullah M., El-Reefy S. "Purification of wet phosphoric acid from ferric ions using modified rice husk". Chem Eng., J 81(2000) 76 -83.

Awwad N., El-Nadi Y., Hamed M. "Successive Processes for Purification and Extraction of Phosphoric Acid Produced by Wet Process", Arab Journal of Nuclear Science and Applications" 46 (2013) 67-77.

Acemioğlu B. "Adsorption of congo red from aqueous solution onto calcium-rich fly ash". J. Could and Interface Sci. 274 (2004) 37 1-379.

Bendada A., Meniai H., Bencheik M. "Modeling of phosphoric acid purification by liquid-liquid extraction". Chem Eng Technol 24 (2001) 1273 -128.

Bishnoi R., Bajaj M., Sharma N., Gupta A. "Adsorption of Cr (VI) on activated rice husk car bon and activated alumin" Bioresour Tech no 191 (2004) 305307. 
Booker A., Streat M. "Proceedings of ion exchange for industry" Imperial College. In: Streat M (Ed.) London (1988).

Chaari I., Fakhfakh E., Chakroun S., Bouzid J., Boujelben N., Feki M., Rocha F., Jamoussi F. "Lead removal from aqueous solution by Tunisian smecitic clay". J. Haz. Mat. 156 (2008) 545-551.

Crank J. "Mathematics of Diffusion". Clarendon Press, Oxford (1970).

Fuentes M., Olaetxea M., Baigorri R., Yamarreno A., Etienne P., Laine P., Ourrz A., Zvin J., Garcia-Mina J. "Main binding sites in-volved in Fe(III) and $\mathrm{Cu}$ (II) complexation in humic-based structures" J. Geochem Explor (2013) 129:14.

Geethakarthi A., Phanikumar B., "Adsorption of reactive dyes from aqueous solutions by tannery sludge developed activated carbon: kinetic and equilibrium studies”. Int. J. Environ. Sci. Technol. 8 (3) (2011) 561-570.

Gerente C., Lee C., Le Cloirec P. "Application of chitosan for the removal of metals from wastewaters by adsorption-mechanisms and models review". Rev. Environ. Sd. Biotechnol. 37 (2007) 41-127.

Grabowska E., Gryglewicz L. "Adsorption characteristics of Congo Red on coal-based mesoporous activated carbon". Dyes Pigm. 74(2007) 34-40.

Hamza W., Chtara C., Benzina M. "Retention of organic matter contained in industrial phosphoric acid solution by raw Tunisian clays: kinetic equilibrium study". J. Chem. (2013). 9- 17.

Hannachi A., Habaili D., Chtara C., Ratel A. "Purification of wet process

phosphoric acid by solvent extraction with TBP and MIBK mixtures". Sep Purif Technol 55 (2007) 212-216.

Inglezakis V., Stylianou M., Gkantzou D., Loizidou M. "Removal of Pb(II) from aqueous solutions by using clinoptilolite and bentonite as adsorbents". Desalination 210 (2007) 248-256.

Khoualdia B., Loungou M., Elaloui E. "Adsorption of organic matter from industrial phosphoric acid $\left(\mathrm{H}_{3} \mathrm{PO}_{4}\right)$ onto activated bentonite". Arabian Journal ofChemistry (2017) 10, S1073-S1080.

Kijkowska R., Pawlowska-Kozinska D., Kowalski Z., Jodko M., Wzorek Z. "Enhanced solvent extraction of cadmium and iron from phos-phoric acid in chloride media" Sep Purif Technol 197 (2002) 205-208.

Komadel P. "Chemically modified smectite". Clay Minerals 38 (2003) 127-138.

Koopman C., Witkamp G. "Extraction of heavy metals from industrial phosphoric acid in a tranverse hollow fiber membrane contractor". Sep Sci Technol 37 (2002)1273-1290.

McKay G., Allen S. J., Can. J. “Chem. Eng.”, 58, 521 (1980). 
MeIIah A., Chegrouche S., Barkat M. "The removal of uranium (VI) from aqueous solutions onto activated carbon: kinetic and thermodynamic investigations" J. of colloid and interface Science. 296 (2006) 434-444.

Mellah A., Chegrouche S., Setti L. "Pretraitement de l'acid ephosphorique industriel par les terres filtrantes Algériennes”. Int JProcess 41(1994) 295303.

Min-Yun C., Ruey-Shin J. "Adsorption of tannic acid, humic acid, and dyes from water using the composite of chitosan and activated clay". J Colloid Interface Sci 18 (2004) 278 -286.

Olyaie E., Banejad H., Afkhami A., Rahmani A., Khodaveisi J. "Development of a cost-effective technique to remove the arsenic contamination from aqueous solutions by calcium peroxide nano-particles". Sep Purif Technol 95 (2012) 10-15.

Slack A. "Phosphoric Acid", vol. 1, Marcel Dekker, New York, 1968.

Steudel A., Batenburg L., Fischer H., Weidler P., Emmerich K. "Alteration of swelling clay minerals by acid activation" AppI. Clay Sci. 44 (2009) - 115.

Taha A., Shreadah A., Ahmed M., Heiba F., "Multi-component adsorption of $\mathrm{Pb}(\mathrm{II}), \mathrm{Cd}(\mathrm{II})$, and $\mathrm{Ni}(\mathrm{II})$ onto Egyptian Na-activated bentonite; equilibrium, kinetics, thermodynamics, and application for seawater desalination". Journal of Environmental Chemical Engineering 4 (2016) 1166-1180.

Tseng W., Juang R. "Kinetic modeling of liquid-phase adsorption of reactive dyes and metal ions on chitosan". Water Res., 35 (3) (2001) 613-61 8 (6 pages).

Weber W., Morris J., Sanitary J. "Eng. Div. Proceed”. Am. Soc. Civil Eng., 90, 79 (1964).

YS H. "Comments on an Evaluation of Copper Biosorption by a Brown Seaweed Under Optimized Condition”. J. Electronic Biotechnol. 7 (2004) 228237.

YS H., Mckay G. "The Kinetics of Sorption of Divalent Metal Ions onto Sphagnum Moss Peat”. Wat. Res. 34(3) (2000) 735-742. 


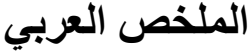

يهذف هذا البحث الي دراسة عملية ادصاص المواد العضويه من حمض الفوسفوريك المركز وذلك باستخدام اطيان صوديوم بنتونيت الخام والمعالج كيميائيا باستخدام حض الكبريتيك او حمض فل الهيدروكلوريك وقد تم تحليل عينات من الطين الخام و المعالج باستخدام جهاز XRD ـ وقد اثتتت الدراسه ان اعلي كفائه لعملية الادمصاص تمت باستخدام الطين المعالج كيميائيا بحمض الكبريتيك. وقد تم ايضا در اسة العو امل المؤثره علي ديناميكية الادمصاص باستخدام اربع نماذج هي:

. (Pseudo-first order, Pseudo-second order, Elovich kinetic and Morris-Weber) وقد وجد ان اعلي نسبه تمثيل تتبع Pseudo-second order. 